\title{
ON AN INEQUALITY OF OPIAL, BEESACK AND LEVINSON
}

R. N. PEDERSON ${ }^{1}$

Levinson [4] recently gave a simple proof of the inequality

$$
\int_{0}^{a}\left|y(x) y^{\prime}(x)\right| d x \leqq \frac{a}{2} \int_{0}^{a}\left|y^{\prime}(x)\right|^{2} d x
$$

valid for absolutely continuous complex-valued $y(x)$ satisfying $y(0)=0$. Equality holds only if $y=b x$ for some constant $b$. Various forms of the inequality had been proved in [1], [2], and [3].

In this note we give an even simpler proof. We first make the preliminary estimate

$$
\int_{0}^{a}\left|y(x) y^{\prime}(x)\right| d x \leqq \int_{0}^{a} \int_{0}^{x}\left|y^{\prime}(t) y^{\prime}(x)\right| d t d x .
$$

Since the integral of a symmetric integrand over the triangle $0 \leqq t \leqq x$, $0 \leqq x \leqq a$, is equal to half of its integral over the square $0 \leqq t \leqq a$, $0 \leqq x \leqq a$, we easily obtain

$$
\begin{aligned}
\int_{0}^{a} \int_{0}^{x}\left|y^{\prime}(t) y^{\prime}(x)\right| d t d x & =\frac{1}{2} \int_{0}^{a} \int_{0}^{a}\left|y^{\prime}(t) y^{\prime}(x)\right| d t d x \\
& =\frac{1}{2}\left[\int_{0}^{a}\left|y^{\prime}(x)\right| d x\right]^{2} .
\end{aligned}
$$

The conclusion then follows immediately from the Schwarz inequality.

\section{REFERENCES}

1. Paul R. Beesack, On an integral inequality of $Z$. Opial, Trans. Amer. Math. Soc. 104 (1962), 470-475.

2. C. Olech, $A$ simple proof of a certain result of $Z$. Opial, Ann. Polon. Math. 8 (1960), 61-63.

3. Z. Opial, Sur une inegalite, Ann. Polon. Math. 8 (1960), 29-32.

4. N. Levinson, On an inequality of Opial and Beesack, Proc. Amer. Math. Soc. 15 (1964), 565-566.

Carnegie Institute of Technology

Received by the editors September 10, 1964.

1 Supported by the National Science Foundation, NSF-G25060. 